\title{
ボリイソブチレン濃厚溶液の粘弾性に及ぼす圧力の影響*
}

$$
\begin{aligned}
& \text { 時 浦 昌 平** 荻 原 定 秀** 山崎保 喜** } \\
& \text { 高 木 武 司** 田端 貫 三** 佐々木愽成** }
\end{aligned}
$$

\section{The Effect of Pressure on the Viscoelasticity of Concentrated Solution of Polyisobutylene}

by

\author{
Shohei Tokiura, Sadahide Ogihara, Yasuki Yamazaki, \\ Takeshi Takaki, Kanzo Tabata and Hiroshige Sasaki \\ (Hirakata Plastics Laboratory, Ube Industries Ltd., Hirakata)
}

\begin{abstract}
A rheometer was designed to measure the viscoelastic behavior of polymer melts and concentrated solutions at high temperature under high pressure. By means of this apparatus, the dynamic viscoelastic properties were measured of concentrated solution (20wt\%) of polyisobutylene which had a viscosity-a verage molecular weight of $6.5 \times 10^{5}$ in decalin. Measurements were made at $40^{\circ} \mathrm{C}$, frequencies being varied from 0.025 to $6.3 \mathrm{sec}^{-1}$, under the pressure in the range from 0 to $1000 \mathrm{~kg} / \mathrm{cm}^{2}$.

With the increase of pressure, both the dynamic viscosity and rigidity increased to the same extent as had been shown in the case of polymer melts. The time-pressure superposition, similar to the usual time-temperature superposition, was made to give a smooth master curve. In order to know how the shift factor depends on pressure, the iso-thermal compressibility of the same sample was determined at $40^{\circ} \mathrm{C}$.

From the above experiments the following conclusions can be made.

(1) The specific volume of the solution can be related to the gauge pressure by Tait's equation,

$$
V_{p}=V_{0}[1-C \log (1+P / B)]
$$

where $V_{p}$ and $V_{0}$ are the specific volumes at gauge pressures $P$ and $0 \mathrm{~kg} / \mathrm{cm}^{2}$ respectively. $B$ and $C$ are constants independent of pressure, and have the values of $760.7 \mathrm{~kg} / \mathrm{cm}^{2}$ and 0.1829 for the solution studied. Assuming that the relative free volume is defined as the ratio of the free volume to the occupied volume, the relative free volume of the solution was derived from Eq. (1),

$$
f_{p}=f_{s}-\left(1+f_{0}\right) C \log \left\{1+\left(P-P_{s}\right) /\left(P_{s}+B\right)\right\}
$$

where $f_{p}, f_{s}$ and $f_{0}$ are the relative free volumes of the solution at gauge pressures $P, P_{s}$ (reference pressure) and $0 \mathrm{~kg} / \mathrm{cm}^{2}$, respectively.

(2) Combining Eq. (2) with Doolittle's equation, the expression for the dependence of the shift factor on pressure can be derived as follows :

$$
\log a_{p}=\frac{1}{2.303 f_{s}} \cdot \frac{C \log \left\{1+\left(P-P_{s}\right) /\left(P_{s}+B\right)\right\}}{f_{s} /\left(1+f_{0}\right)-C \log \left\{1+\left(P-P_{s}\right) /\left(P_{s}+B\right)\right\}}
$$

This expression shows satisfactory agreement with experimental results.

(Received Dec. 11, 1967)

\section{1 緒 言}

加圧された高分子溶融物および高分子濃厚溶液が示 す物理的挙動について，最近いろいろと研究されてい

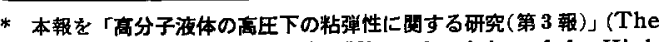
Effect of Pressure on the Viscoelasticity of the High Polymer Liquids, III) とする

原䅧受理 昭和42年12月11日

***宇部興産(株)枚方樹脂研究所 枚方市中宮北町
るが，粘弾性に関するものはその重要性にもかかわら ず数が少ない，筆者らは圧力が高分子溶融物および高 分子濃厚溶液の粘弾性に及ほす影響を明らかにするた めに，加王型溶融粘弾性測定装置を試作した。

この装置を使って高分子溶融物の動的粘性および動 的弾性に及ぼす圧力の影響を測定し，测定結果に対し て時間-温度の重合せに類似した時間一圧力の重合せが 
道用され，なめらかな合成曲線の得られることが明ら かになった。.この重合せの結果得られたシフトブテク ター $a_{p}$ 考察するに際して，粘弾性測定とは別に等 温圧縮実験を行ない，試料の比容と正力の関係を求め た。この関係は二つの定数を適当に定めれば Tait の 実験式によって上く記述されることが確認された，次 に, 圧力による粘弹性および比容（あるいは自由体積 分率)の变化を Doolittle の粘度式を用いて関係づけ， シフトファクターの压力低存性を表わす関倸式を導い た.この関係式はシリコンオイルのシフトファクター の圧力による変化老上く説明し，その際基準圧力にお ける試料の自由体積分率の值を求めることができた，

溶液は溶融物と違って溶媒を含んでいるので，溶融物 について観察された上の諸事実がはたして溶液に対し てもあてはまるかどうか恃非常に興咮のある点である。

本報においてはこの点を明らかにするために，ポリ イソブチレンのブカリン濃厚溶夜 (20 wt \%) の動的粘 弾性を上の装置を用いて測定温度 $40^{\circ} \mathrm{C}$, 湘定圧力箱 团 $0 \sim 1000 \mathrm{~kg} / \mathrm{cm}^{2}$ (ゲージ圧)，角周波数 $0.025 \sim 6.3$ $\mathrm{sec}^{-1}$ にわたって測定し，その結果について考察を進 めた。

\section{2 実験}

2.1. 試 料

使用した試料はポリインブチレン(Vistanex MML100 ; Esso Standard Oil Co. 製)をデカリン中に 20 $\mathrm{wt} \%$ だ溶解した浱厚溶液である。

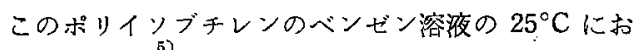
ける極限粘度数から求めた平均分子量は $6.5 \times 10^{5}$ て ある、をた，溶媒として用いたデカリンのシスーおよ びトランスー異性体の含有率は，風折率法によってそ れぞれ 53.0 および $47.0 \mathrm{wt} \%$ であると推定された。 なお，シスーおよびトランスー異性体の粘度および比 容の圧力による变化については Hogenboom らの研究 結果がある。

\section{$2 \cdot 2$ 測 定}

動的粘弹性の測定には，筆者らが試作した加圧型溶 融粘弹性測定装置を外筒強制标じれ振動レオメータと して使用した，测定温度は $40^{\circ} \mathrm{C}$, 測定圧力は $0 \mathrm{~kg} / \mathrm{cm}^{2}$ (常仕)から $200 \mathrm{~kg} / \mathrm{cm}^{2}$ ごとに $1000 \mathrm{~kg} / \mathrm{cm}^{2}$ まで夜 化させた，温度および生力設定の精度はそれぞれ䄪 $\pm 0.2^{\circ} \mathrm{C}$ および約 $\pm 5 \mathrm{~kg} / \mathrm{cm}^{2}$ である。 また，测定角 周波数領域は約 $0.025 \sim 6.3 \mathrm{sec}^{-1}$ にわたった。

同時に行なった等温圧縮実験に使用した装置は，加 压に油圧ポンプを利用したプランジャーシリンダ式の 装置である。測定温度は $40^{\circ} \mathrm{C}$ (一定), 测定圧力領域 は $0 \sim 1400 \mathrm{~kg} / \mathrm{cm}^{2}$ (ゲージ压)にわたった。

\section{‘3 結果および考察}

各圧力下で測定された動的粘性率 $\eta^{\prime}$ ，および動的弾

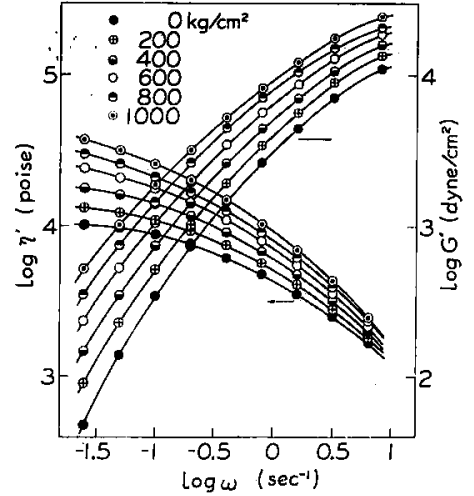

Fig. 1. Frequency dependence of $\eta^{\prime}$ and $G^{\prime}$ under various pressures for polyisobutylene in decalin at $40^{\circ} \mathrm{C}$.

性率 $G^{\prime}$ の角周波数 $\omega$ に対する低存性を Fig. 1 に示す。 この図の 光および $G^{\prime}$ 曲線は，压力を高くするとき高 分子溶融物の場合にみられたと同程度に增大している。

この測定結果に対して，時間一温度の重合せと類似 した時間一压力の重合せを行なった。すなわち，0 kg/ $\mathrm{cm}^{2}$ を基準圧力 $P_{s}$ とし， $\log G^{\prime} \sim \log \omega$ 曲線の場合に は，任意の圧力 $P$ における曲線を $\log \omega$ 軸に平行に移 動させ，一力 $\log \eta^{\prime} \sim \log \omega$ 曲線の場合にはこう配 -1 をもつ直線に沿って移動させた，その際，圧力に上る 試料の密度の変化は考慮しなかった，重合せの結果得 られた合成曲線を Fig. 2 に示す。因に示すように，

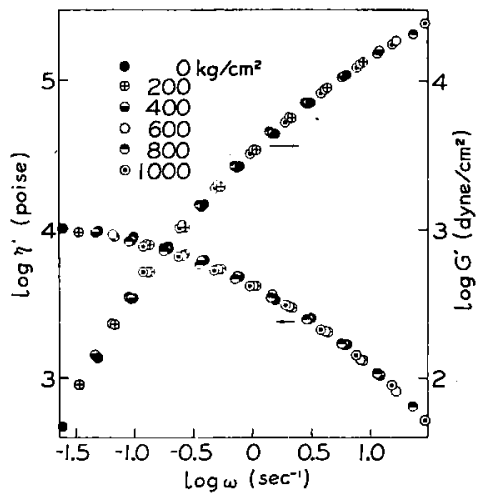

Fig. 2. Master curves of $\eta^{\prime}$ and $G^{\prime}$ for polyisobutylene in decalin at $40^{\circ} \mathrm{C}$. The reference pressure is $0 \mathrm{~kg} / \mathrm{cm}^{2}$.

時間一圧力の重合せはなめらかな合成曲線を与え，少 なくともこの圧力，温度および角周波数領域において はこの重合せが满足に行なえることを示している.

$\log G^{\prime} \sim \log \omega$ 曲線の水平方向の移動量として求めら れたシフトファクター $a_{p}$ の值は, $\log \eta^{\prime} \sim \log \omega$ 曲線 の水平または垂直方向の移動量として求められた $a_{p}$ の値とよく一致した. シフトファクター $a_{p}$ の圧力に 
Table I. Shift factor $a_{p}$ at different pressures for polyisobutylene in decalin. The reference pressure is $0 \mathrm{~kg} / \mathrm{cm}^{2}$ (at $40^{\circ} \mathrm{C}$ ).

\begin{tabular}{c|c|c|c|c|c|c}
\hline$P\left(\mathrm{~kg} / \mathrm{cm}^{2}\right)$ & 0 & 200 & 400 & 600 & 800 & 1000 \\
\hline$a_{p}$ & 1.000 & 1.382 & 1.908 & 2.652 & 3.635 & 4.885 \\
\hline
\end{tabular}

よる変化を Table I に揭げる。

筆者らはこのような高分子泎厚溶液の粘弹性に及ぼ す珐力の影響克考察するために，粘弹性測定亡は别に 等温圧縮実験を行ない, 試料の此容 $v$ と王力 $P(ケ ゙ ー$ ジ圧)の関係について検討した.

この泰驗の結果, 此容 $v$ と王力 $P$ の関係は下のTait の実験式によってよく記述されることができることが わかった。

$$
v_{p}=v_{0}\left\{1-C \log \left(1+\frac{P}{B}\right)\right\}
$$

ここで， $v_{p}$ および $v_{0}$ はゲージ正力Pおよび $0 \mathrm{~kg} / \mathrm{cm}^{2}$ における試料の比容であり，BおよびCは圧打に依存 しない定数である。

Fig. 3 に等温圧縮実験 $\left(40^{\circ} \mathrm{C}\right)$ によって求められた 試料の比容 $v$ とゲージ王力 $P$ の関係龺示す．この図に おいて○印は測定値を示し，また奏線で描かれた曲線 は(1)式の定数 $B$ 拉よびCを

$$
B=760.7 \mathrm{~kg} / \mathrm{cm}^{2}, C=0.1829
$$

としたときの計算曲線である。この曲線は各測定值を よく貫いており，㞋力による試料の比容の変化は $40^{\circ} \mathrm{C}$ $0 \sim 1400 \mathrm{~kg} / \mathrm{cm}^{2}$ の圧力領域において(1)式でよく記述 されることを示している。

(1)式よりゲージ圧力 $P_{s} \mathrm{~kg} / \mathrm{cm}^{2}$ (基準圷力)におけ る比容 $v_{s}$ は

$$
v_{s}=v_{0}\left\{1-C \log \left(1+\frac{P_{s}}{B}\right)\right\}
$$

で表わされる、したがってこの式と(1)式から $v_{p}$ 次の式でも記述できる.

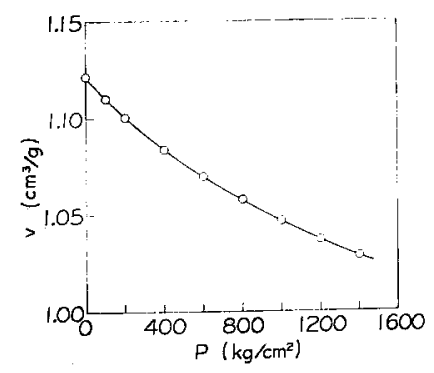

Fig. 3. The variation of the specific volume with pressure for polyisobutylene in decalin at $40^{\circ} \mathrm{C}$. The open circles show the experimental values, and the solid curve calculated ones from Eq. (1).

$$
v_{p}=v_{s}-v_{0} C \log \left(1+\frac{P-P_{s}}{P_{s}+B}\right)
$$

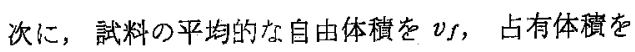
$v^{*}$ とすれば，試料の平均的な自由体積分率 $f$ および 比容 $v$ は Doolittle に従って

$$
\begin{aligned}
& f=v_{f} / v^{*} \\
& v=v^{*}+v_{f}
\end{aligned}
$$

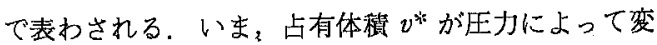
化しないと仮定すると，(3)式と(4)式から平均的な自由 体積分率 $f$ の圧力依存性は次の式で表わされる。

$$
f_{p}=f_{s}-\left(1+f_{0}\right) C \log \left(1+\frac{P-P_{s}}{P_{s}+B}\right)
$$

ここで $P_{s}$ は時間一圧力の重合せの際に選ばれた基準压 力であり， $f_{p} ， f_{s}$ 执よ゙ $f_{0}$ はそれぞれゲージ圧力 $P$, $P_{s} お よ ひ ゙ ~ 0 \mathrm{~kg} / \mathrm{cm}^{2}$ における試料の平均的な自由体 積分率である。

(5)式と Doolittle の粘度式

$$
\eta=A \exp \left(\frac{B^{\prime}}{f}\right) \div A \exp \left(\frac{1}{f}\right)
$$

(ただしAおよび $B^{\prime}$ は定数である， $B^{\prime}$ は 1 に近い

、值であるからここでは近似的に 1 とした） を用いると，時間王力の重合せのシフトファクター $a_{p}$ の王力依存性を示す次の式が得られる.

$$
\therefore \quad \log a_{p}=\frac{1}{2.303 f_{s}} \cdot \frac{C \log \left(1+\frac{P-P_{s}}{P_{s}+B}\right)}{\frac{f_{s}}{1+f_{0}}-C \log \left(1+\frac{P-P_{s}}{P_{s}+B}\right)}
$$

基準圧力 $P_{s}$ として $0 \mathrm{~kg} / \mathrm{cm}^{2}$ を選ぶとき，(7)式は

$$
\log a_{p}=\frac{1}{2.303 f_{0}} \cdot \frac{C \log \left(1+\frac{P}{B}\right)}{\frac{f_{0}}{1+f_{0}}-C \log \left(1+\frac{P}{B}\right)}
$$

となる、上の式からわかるように，1/log $a_{p}$ を $C \log (1+P / B)$ の逆数に対してプロットすれば直線が 得られ，その綐軸上の切片は $-2.303 f_{0}$ ，こう配は $2.303 f_{0}^{2} /\left(1+f_{0}\right)$ である。したがって, 実験データか ら $f_{0}$ を求めることがでさる. Table I に揭げたシフ トファタター $a_{p}$ の值を用い，この方法によって決定 された試料の $0 \mathrm{~kg} / \mathrm{cm}^{2}$ (常圧)， $40^{\circ} \mathrm{C}$ における平均 的な自由体積分率 $f_{0}$ の值は 0.279 であった。このよ うにして決定された $f_{0}$ の值を(7)式に代入して $\log a_{p}$ とPの関係を求めると，Fig. 4 に示した曲線になる。 図の○印は実測值で両者はよく一致している。この事 㤗は，高分子溶液の粘弹性に及ぼす圧力の影響が上の ような取り报いによってよく説明されることを示して いる.

\section{4 結 諭}

ポリイソブチレンのデカリン溶液 (20 wt \%) を試料 として，その動的粘弾性を $40^{\circ} \mathrm{C}, 0 \sim 1000 \mathrm{~kg} / \mathrm{cm}^{2}$ の 


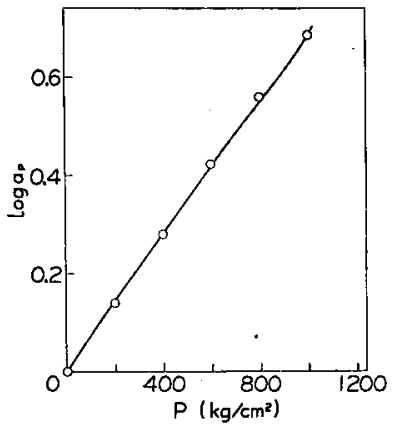

Fig. 4. Pressure dependence of shift factor $a_{p}$ for polyisobutylene in decalin at $40^{\circ} \mathrm{C}$. The reference pressure is $0 \mathrm{~kg} / \mathrm{cm}^{2}$. The open circles show experimental values and the solid curve calculated ones from Eq. (7)'.

圧力領域において測定し，次の結諭を得た。

(1) 試料の動的粘性率および動的弾性率はとともに压 カの上年に伴って增大し，その程度は以前報告した低 密度ポリエチレン溶融物およびシリコンオイルにみら れたと同程度である。

(2) 上の測定結果に対して，時間-温度の重合せと 類似の時間一王力の重合せを行なった。この重合せは 測定領域内で満足に行なわれ，なめらかな合成曲線を 与えた。これは既報の低密度ポリエチレン溶融物お
よびシリコンオイルの場合とまったく同様てある。 $\log \eta^{\prime} \sim \log \omega$ 曲線の移動量として求めた $a_{p}$ は, $\log G^{\prime}$ $\sim \log \omega$ 曲線の移動から求めた $a_{p}$ とまったく一致し た.

（3）同時に行なった $40^{\circ} \mathrm{C}$ における等温厈縮実験の 結果から得られた試料の比容と开力の関係と, 自由体 積分率を使った Doolittleの粘度式から時間一圧力の重 合せにおけるシフトファクターの圧力侤存性を示す関 係式が睢かれた。この関係式住高分子濃厚溶液の平均 的な自由体積分率を含んでいるが，シフトファクター $a_{p}$ の圧力による変化をよく記述することができる.

(4) 上の関係式と実駼值から求めた $40^{\circ} \mathrm{C}, 0 \mathrm{~kg} / \mathrm{cm}^{2}$ (常压)における試料の平均的な自由体積分率は 0.279 であった。

最後に本研究に関してご指導をいただいた京都大学 小野木重治救授に感謝する。

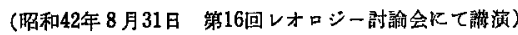

\section{参 考 文 献}

1）時浦昌平5，第16回高分子学会年会，四 I-22(1967),

2) 時浦昌平5, 第16回高分子学会年会, III I-23(1967).

3) Wood, L.A., J. Polymer Sci., B 2, 703 (1964):

4) Doolittle, A.K., J. Appl. Phys., 22, 1031 (1951).

5）日本化学会縟, “实駰化学講座 8”, p. 151 (1956).

6) Hogenboom, D.L., W. Webb, and J.A. Dixon, J. Chem. Phys., 46, 2586 (1967). 